\title{
Molecular Interactions in Binary Surfactant Solutions: Effect of Ionic Counterpart
}

\author{
Olga Kochkodan*, Nataliya Slobodianiuk, Lidiya Kovshun, Olena Khyzhan \\ National University of Life and Environmental Sciences of Ukraine, Kyiv, Ukraine. \\ *Corresponding author: Olga Kochkodan, email: okochkodan@hotmail.com
}

Received Febraury $8^{\text {th }}, 2020$; Accepted May $1^{\text {st }}, 2020$.

DOI: http://dx.doi.org/10.29356/jmcs.v64i3.1153

\begin{abstract}
The effect of intermolecular interactions on processes of micelle formation and adsorption in binary mixtures of non-ionic Triton X100 (TX100) with ionic sodium dodecyl sulfate and dodecylpyridinium bromide surfactants was studied. The ionic surfactants have identical hydrophobic alkyl chain and different hydrophilic groups. A feature of the used binary surfactant mixtures is that critical micelle concentrations and surface activity of the individual components are considerably different. A synergetic effect of decreasing of the surface tension was found in the surfactant mixtures. It was shown that the mixed adsorption layers and the micellar phases are enriched with the nonionic surfactant. For both sodium dodecyl sulfate/TX100 and dodecylpyridinium bromide/TX100 systems, the synergetic effects were most pronounced at a high molar fraction of the nonionic surfactants in the mixture. By using the Ruben-Rosen model, molecular interaction parameters in the mixed micelles $\beta^{m}$, and in the adsorption layers $\beta^{\sigma}$ were evaluated. As was shown $\beta^{m}$ and $\beta^{\sigma}$ parameters to be notably higher for sodium dodecyl sulfate/TX100 mixture.

Keywords: Triton X100; dodecylpyridinium bromide; sodium dodecyl sulfate; molecular interactions; mixed adsorption layer.

Resumen. Se estudia el efecto de las interacciones intermoleculares en el proceso de formación y adsorción de micelas en mezclas binarias de Triton X100 (TX100), no iónico, con dodecil sufato de sodio y bromuro de dodecil piridinio, ambos iónicos, como surfactantes. Los surfactantes iónicos tienen cadenas alquílicas hidrofóbicas idénticas y grupos hidrofílicos diferentes. Una característica de las mezclas binarias de surfactantes que se utilizaron es que las concentraciones micelares críticas y la actividad superficial de los componentes individuales es considerablemente diferente. Se encontró un efecto sinérgico de decremento de la tensión superficial en las mezclas de surfactantes. Se muestra que las capas mixtas de adsorción y las fases micelares están enriquecidas con surfactante no iónico. Tanto en el sistema dodecil sufato de sodio/TX100 como en el caso de bromuro de dodecil piridinio/TX100, los efectos sinérgicos fueron más pronunciados en las mezclas con fracciones molares altas de los surfactantes no iónicos. Utilizando el modelo de Ruben-Rosen, se evaluaron los parámetros de interacción molecular en las micelas mezcladas $\beta^{m} \mathrm{y}$ en las capas de adsorción $\beta^{\sigma}$. Se muestra que los parámteros $\beta^{m}$ son $\beta^{\sigma}$ son notablemente mayores en la mezcla de dodecil sufato de sodio/TX100.

Palabras clave: Triton X100; bromuro de dodecil piridinio; dodecil sufato de sodio; interacciones moleculares; capa mixta de adsorción.
\end{abstract}




\section{Introduction}

Investigation of micelle formation and adsorption processes in the surfactant mixtures is one of the important topics of colloid chemistry. Currently the surfactant mixtures are broadly employed in different colloid-chemical processes such as laundering, flotation, emulsion polymerization, oil recovery, stabilization of colloids and nanoparticles in pharmaceutical and cosmetic formulations [1,2]. It is known that the mixed surfactant systems often have properties that are significantly different than ones for individual surfactants [2,3]. As a result of complex interactions amid the components, mixed micelles in aqueous solutions and mixed adsorbed layers on the solution/air boundary are formed in the multicomponent surfactant systems [1-3].

Mixed adsorption and micelle formation in binary surfactant systems have been widely discussed in the literature [4-18]. It was reported that the surfactants of the similar chemical structure usually behave in their mixtures similarly to the ideal surfactant systems [3-6]. However, the mixtures of structurally different compounds often display non-ideal behaviour [7-18]. In many cases, composition of a mixed adsorbed layer can considerably differ if compare to composition of the bulk solution. As a result, deviations from lineal dependencies between surface tension, concentration of micelle formation, Gibbs adsorption energy on the one hand and the surfactants composition on the other hand were found [2,7-12]. Depending on the surfactants type, amplification or weakening of the mutual surfactants influence on the bulk and surface-active properties of the mixed solutions are observed [8,13-18].

Though different aspects of the surfactant mixtures have been widely investigated, the effect of many factors on the surfactants' adsorption from multicomponent surfactant mixtures as well as composition of the mixed adsorbed layers are not yet clear. This is especially relevant for the surfactant mixtures where single surfactants have notably different surface activities.

The main goal of this work is to study the molecular and thermodynamic parameters of the interactions in the mixed surfactants systems, where critical micelle concentration $(C M C)$ of single counterparts and their surface activities are considerably different. For this purpose, the mixtures of nonionic Triton X-100 (TX100) with ionic sodium dodecyl sulfate (SDS) and dodecylpyridinium bromide (DDPBr) surfactants were used. A better insight into the molecular interactions in such surfactants systems would be beneficial for predicting their adsorption behaviour and surface-active properties.

\section{Experimental}

The nonionic surfactant TX100, which is oxyethylated octylphenol (the molecular formula is $\mathrm{C}_{8} \mathrm{H}_{17} \mathrm{C}_{6} \mathrm{H}_{4} \mathrm{O}\left(\mathrm{CH}_{2} \mathrm{CH}_{2} \mathrm{O}\right)_{n} \mathrm{H}$ ) with the degree of oxyethylation $\mathrm{n}=9-10$, the cationic surfactant DDPBr (the general formula is $\mathrm{C}_{12} \mathrm{H}_{25} \mathrm{NC}_{5} \mathrm{H}_{5} \mathrm{~B} \Gamma$ ) and the anionic surfactant SDS of the (the molecular formula is $\mathrm{C}_{12} \mathrm{H}_{25} \mathrm{SO}_{3} \mathrm{Na}$ ) were used. The surfactants were puschased from Sigma-Aldrich (USA). SDS and TX100 were used as received, while DDPBr was recrystallized from methylethylketone prior employing in the experiments.

The surfactant solutions were studied within the concentrations of $1.0 \times 10^{-5}-5.0 \times 10^{-4} \mathrm{M}$ for TX100 and $1.0 \times 10^{-5}-1.5 \times 10^{-2} \mathrm{M}$ for the ionic surfactants, respectively. The solutions were prepared with distilled water $(\mathrm{pH}$ of the solutions was 6.3-6.5). The surfactant mixtures of different composition were prepared by appropriate mixing of the individual surfactant solutions. TX100 mole fractions in the mixtures $\left(\alpha_{T X 100}\right)$ were $0.2,0.4,0.6$ and 0.8 .

The mole fractions of TX100 surfactant in aqueous solutions and in the mixed adsorption layers were calculated as:

$$
\alpha_{T X 100}=\frac{C_{T X 100}}{C_{i}+C_{T X 100}}
$$




$$
\alpha_{T X 100}^{\sigma}=\frac{C_{T X 100}^{\sigma}}{C_{i}^{\sigma}+C_{T X 100}^{\sigma}}
$$

where, $\alpha_{T X 100}$ and $\alpha_{T X 100}^{\sigma}$ are the TX100 mole fractions in the solution and in the mixed adsorption layer at a boundary between an aqueous solution and air, respectively, $C_{T X 100}$ and $C_{i}$ are the concentrations of TX100 and ionic surfactants in the mixed solution, $C_{T X 100}^{\sigma}$ and $C_{i}^{\sigma}$ are concentrations of TX100 and ionic surfactants at an interface between an aqueous solution and air.

Measurement of the surface tension $(\sigma)$ was carried out by using Wilhelmy method [19]. A platinum plate was submerged in a surfactant solution and then gently dragged out. The measured pulling out force is correlate with the surface tension. The cleanliness of the plate was evaluated by measuring surface tension of the bidistilled water $\left(\sigma=72.5 \mathrm{~mJ} \mathrm{~m}^{-2}\right)$. For each solution the measurements were conducted five times and the average readings were taken. The experimental deviation was $\pm 0.5 \mathrm{~mJ} \mathrm{~m}^{-2}$.

The $C M C$ value was evaluated from the break point on surface tension $(\sigma)$ versus the surfactant concentration plot [19]. The surface tension decreases with the solution concentration, until the surfactant's concentration reaches the $C M C$ value. After this point, the surface tension values are practically constant.

\section{Results and discussion}

The surface tension isotherms for single and mixed solutions at different molar ratios of the components are shown in Fig. 1. Based on these data, the key colloid-chemical parameters of DDPBr, TX100 and SDS surfactants were calculated and displayed in Table 1.

Table 1. The values of $C M C$, surface surfactant's excess $\Gamma^{\sigma}{ }_{\max }$, surface area per a surfactant molecule $S_{0}$ at adsorption saturation, Gibbs free energies of adsorption $\Delta G^{0}$ ads and micelle formation $\Delta G^{0}$ mic for the used surfactants.

\begin{tabular}{|c|c|c|c|c|c|}
\hline Surfactant & $C M C \times 10^{3}, \mathrm{~L}^{-1}$ & $\begin{array}{c}\Delta G_{m i c}^{0} \\
\mathrm{~kJ} \mathrm{~mol}^{-1}\end{array}$ & $\Gamma_{\max }^{\sigma} \times 10^{6}, \mathrm{~m}^{-2}$ & $\begin{array}{c}S_{o,}, \\
\mathbf{n m}^{2}\end{array}$ & $\begin{array}{c}\Delta G^{0}{ }_{a d s} \\
\mathrm{~kJ} \mathrm{~mol}^{-1}\end{array}$ \\
\hline TX100 & $0.24 \pm 0.02$ & $-30.7 \pm 0.5$ & $5.54 \pm 0.30$ & $0.33 \pm 0.01$ & $-32.1 \pm 0.5$ \\
\hline SDS & $8.10 \pm 0.67$ & $-23.6 \pm 0.4$ & $3.56 \pm 0.15$ & $0.44 \pm 0.02$ & $-25.4 \pm 0.4$ \\
\hline DDPBr & $11.20 \pm 0.93$ & $-20.5 \pm 0.3$ & $2,78 \pm 0.10$ & $0.61 \pm 0.03$ & $-22.3 \pm 0.3$ \\
\hline
\end{tabular}

The surfactant's concentration at the interface $\left(\Gamma^{\sigma}\right)$ was calculated be using the fundamental Gibbs adsorption equation $[1,19]$ :

$$
\Gamma^{\sigma}=-\frac{C}{i R T} \frac{d \sigma}{d C}=-\frac{1}{i R T} \frac{d \sigma}{d \ln C}
$$

where, $i$ is stand for 1 and 2 for nonionic and ionic surfactants, respectively.

When $d \sigma / d \ln C=\max$, than $\Gamma^{\sigma}$ reaches its maximum value, and $\Gamma^{\sigma}=\Gamma^{\sigma} \max$.

The surface area $S_{0}\left(\mathrm{~nm}^{2}\right)$ per a surfactant molecule in the saturated adsorption layer was calculated by the equation:

$$
S_{0}=\frac{10^{18}}{\Gamma_{\max }^{\sigma} N_{A}}
$$


where, $N_{A}$ corresponds to the Avogadro number, while $\Gamma^{\sigma}{ }_{\max }$ is the maximal adsorption value.

Fig. 1 shows that in case of the surfactant mixtures and for the wide range of molar ratios of the surfactants in the solutions the surface tension isotherms are mostly positioned between the surface tension isotherms for the appropriate individual surfactants.
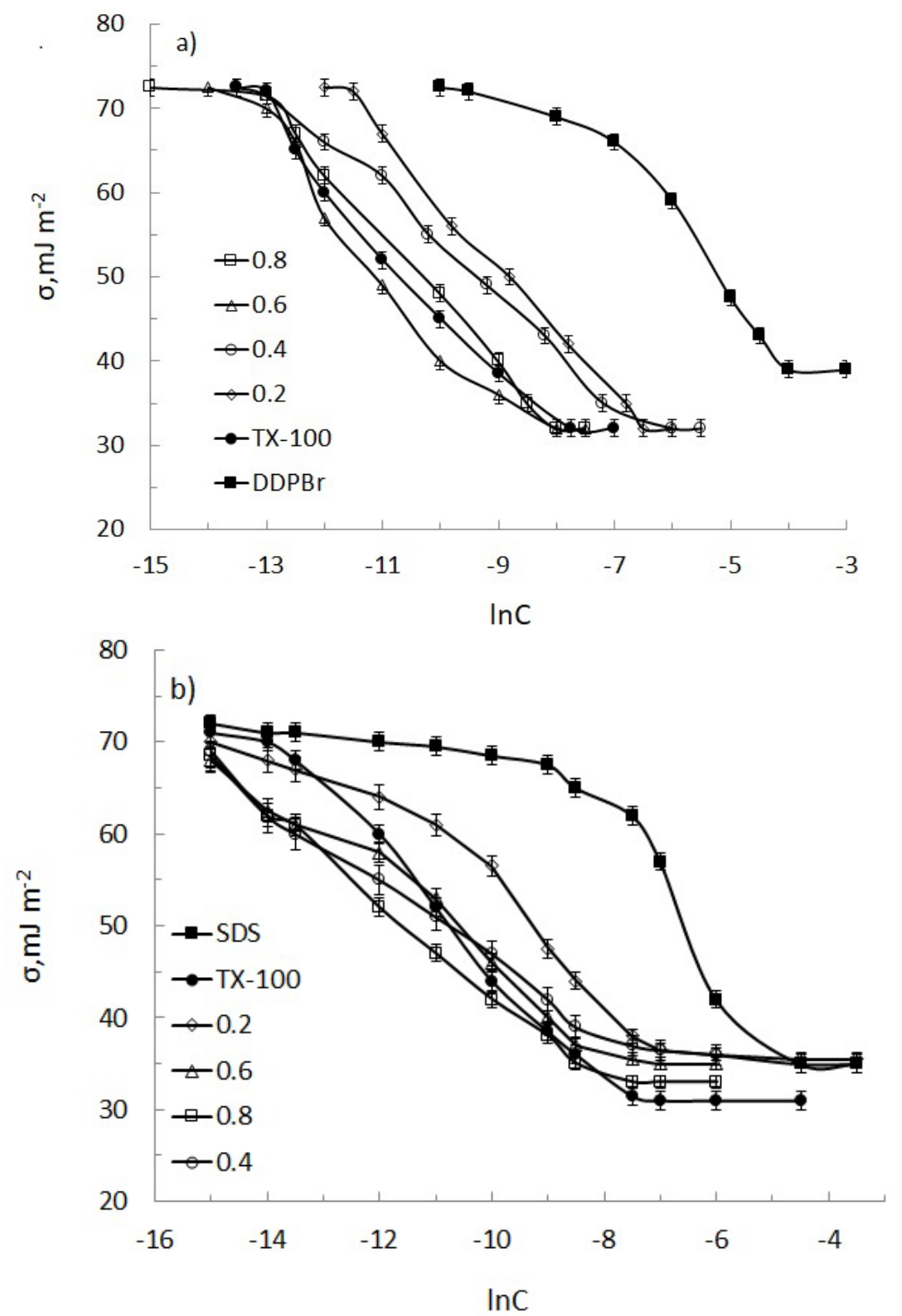

Fig. 1. Surface tension in the surfactant systems: (a) DDPBr/TX100 and (b) SDS/TX100 at different molar fraction of TX100 $\left(\alpha_{\mathrm{Tx} 100}\right)$ in the binary systems.

Fig. 1(a) shows that the surface tension isotherms in TX100/DDPBr mixture at $\alpha_{T X 100}=0.6$ and in SDS/TX100 system at $\alpha_{T X 100}=0.8$ are located below the isotherm for the nonionic surfactant. For SDS/TX100 mixture, the initial sections of the isotherms at $\alpha_{T X 100}=0.2-0.8$ are situated under the isotherm for the single 
nonionic surfactant. Thus, the mixed SDS/TX100 system reduces the surface tension more efficiently, compared to the nonionic surfactant. These findings indicate that there are specific interactions among the counterparts in the mixed adsorption layer on the air/solution boundary.

The $C M C$ values for the surfactant mixtures were evaluated by using the Clint's equation for an ideal system $[1,20]$ :

$$
1 / C M C=\alpha_{1} / C M C_{1}+\alpha_{2} / C M C_{2}
$$

where, $\alpha_{1}$ and $\alpha_{2}$ correspond to molar fractions, while $C M C_{1}$ and $C M C_{2}$ correspond to $C M C$ values for single surfactants 1 and 2 .

Fig. 2 shows the dependences of experimental and calculated values of $C M C$ versus the composition of the surfactant mixtures. The presented data indicate that calculated and experimental $C M C$ values for the surfactants mixtures match well. Thus, the obtained results specify that there are no deviations from the ideal behaviour in the surfactants mixtures at the given surfactants' composition.
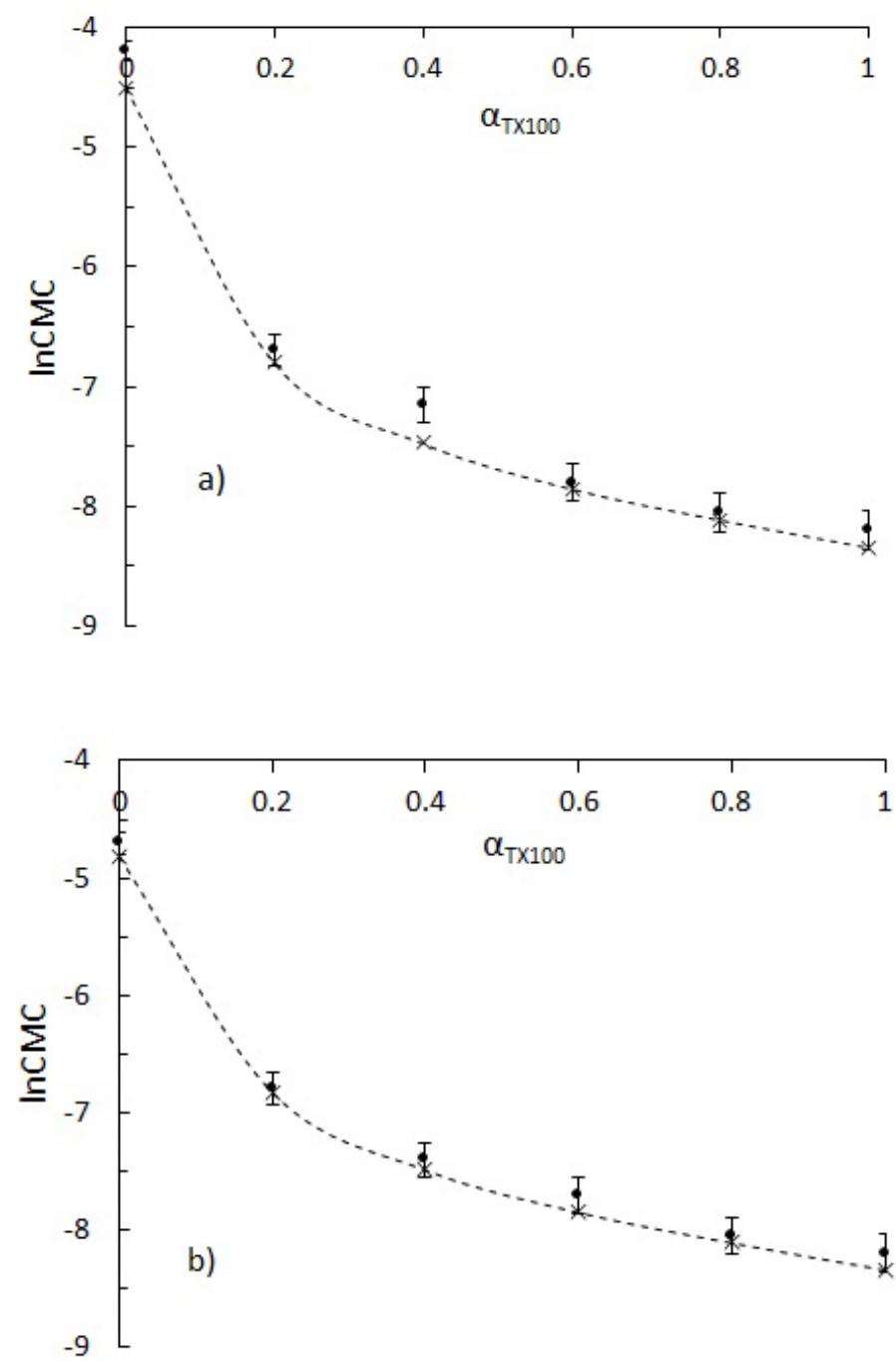

Fig. 2. $C M C$ values of the surfactants mixtures versus composition of DDPBr/TX100 (a) and SDS/TX100 (b) mixtures: (---) - calculation for the ideal system, $(\bullet)$ - experimental data. 
The Ruben-Rosen model was employed to determine the parameters of intermolecular interactions during adsorption and micelle formation in the surfactant mixtures $[7,21]$. The parameters of intermolecular interactions in micelles $\beta^{m}$ and in adsorption layers $\beta^{\sigma}$, changes in Gibbs energies of micelle formation $\Delta G_{m}$ and adsorption $\Delta G_{a d s}$ as well as composition of the adsorption layers and mixed micelles, were evaluated from the experimental data on surface tension and $C M C$ in the surfactant systems.

The $\beta^{m}$ coefficient was evaluated as follows [2,7]:

$$
\beta^{m}=\frac{\ln \left(\alpha_{1} C M C / x_{1}^{m} C M C_{1}\right)}{\left(1-x_{1}^{m}\right)^{2}}
$$

where $C M C_{l}$ and $C M C$ are $C M C$ values for surfactant 1 and the surfactant mixture; $x_{1}^{m}$ and $\alpha_{l}$ are the molar fractions of surfactant 1 in the mixed micelle and in the aqueous solution.

To evaluate the mixed micelle composition, it is sufficient to know $x_{1}^{m}$ parameter, which was calculated as $[7,21]$ :

$$
\left(x_{1}^{m}\right)^{2} \ln \left(\frac{\alpha_{1} C M C}{x_{1}^{m} C M C_{1}}\right)=\left(1-x_{1}^{m}\right)^{2} \ln \left(\frac{\left(1-\alpha_{1}\right) C M C}{\left(1-x_{1}^{m}\right) C M C_{2}}\right)
$$

where, $x_{1}^{m}$ and $\alpha_{l}$ are the molar fractions of surfactant 1 in the micelle and in the solution; $C M C, C M C_{l}$, and $C M C_{2}$ are $C M C$ values of the surfactant mixture, surfactant 1 and 2, respectively.

To evaluate the parameters of molecular interaction in a binary surfactant mixture as well as mixed micelles composition it is sufficient to experimentally find out $C M C$ values both for the individual surfactants and the surfactant mixture. Note that $\beta^{n}$ parameter is an indicator of the non-ideal surfactant's behaviour during micelle formation. The negative or positive values of $\beta^{n}$ are related to negative or positive deviancy from ideal behaviour, whereas the absolute $\beta^{n}$ value reflects the intensity of molecular interactions. Attractive interactions between the counterpart molecules are indicated by negative $\beta^{n}$ values, whereas repulsive molecular interactions are specified by positive $\beta^{n}$ readings.

The standard free energy of micelle formation $\Delta G^{0}$ mic for the singe surfactant was calculated as [22]:

$$
\Delta \mathrm{G}^{0}{ }_{m i c}=R T \ln C M C
$$

where, $R$ is the universal gas constant $\left(\mathrm{J} \mathrm{mol}^{-1} \cdot \mathrm{K}^{-1}\right), T$ is temperature $(\mathrm{K})$ and $C M C$ is $C M C$ value for a given surfactant $\left(\mathrm{mol} \mathrm{L}^{-1}\right)$.

It was shown that when the concentration of the surfactant mixtures is $\leq 0.01 \mathrm{~mol} \mathrm{~L}^{-1}$, equation (8) also gives reasonable $\Delta G^{0}$ mic values, which correlate well with $\Delta G^{0}$ mic values obtained by means of using other models [23].

The change of $\Delta G^{0}$ ads parameter also reflects the surfactant's capability to adsorb at the phase interface. If a saturated adsorption layer is formed at a bulk surfactant concentration $\leq 0.01 \mathrm{~mol} \mathrm{~L}^{-1}, \Delta G^{0}$ ads is evaluated by the Rosen-Aronson equation [21]:

$$
\Delta \mathrm{G}^{0} \text { ads }=2.303 R T \log \frac{C}{\varpi}-N_{A} \pi A_{m}
$$

where, $A_{m}$ is the maximal area for a surfactant molecule at the air/solution interface $\left(\mathrm{m}^{2}\right) ; \infty$ is a number of water moles per $L$ and $\pi$ correspond to surface tension at a given concentration $C$, that is needed to reach the $A_{m}$ value.

Table 1 displays the $\Delta G^{0}$ ads values calculated from equation (9). It is seen from the data that $\Delta G^{0}$ ads (by its absolute value) exceed $G^{0}{ }_{m i c}$ and this difference is the largest for the nonionic surfactant. The calculations were conducted given the saturated surface layer to be formed: $\Gamma^{\sigma}=\Gamma^{\sigma}{ }_{\max }, C=C M C, A_{m}=S_{0}$. The obtained values of $\Delta G^{0}$ ads demonstrate larger sorption capacity and, hence higher surface activity of TX-100, compared to the ionic surfactants. 
The calculated intermolecular interaction parameter $\beta^{m}$, micelle composition and $\Delta G_{m i c}$ values are displayed in Table 2. Negative values of $\beta^{m}$ parameter in Table 2 indicate that notable intermolecular interactions amid the surfactants in the mixed solutions take place. Also, as seen in Table 2 TX100 molecules dominate in the mixed micelles. The schematic presentation of the mixed DDPBr/TX100 and SDS/TX100 micelles in the aqueous solution is shown in Fig. 3.

Table 2. Molar micelle fraction $x^{m}$ of TX100, molecular parameter $\beta^{m}$ and $\Delta G_{m i c}$ values in the surfactant's mixtures.

\begin{tabular}{|c|c|c|c|c|}
\hline \multicolumn{5}{|c|}{ DDPBr/TX100 } \\
\hline$\alpha_{T X 100}$ & 0.2 & 0.4 & 0.6 & 0.8 \\
\hline$x^{m}$ & $0.83 \pm 0.02$ & $0.85 \pm 0.02$ & $0.82 \pm 0.02$ & $0.87 \pm 0.02$ \\
\hline$\beta^{m}$ & $-1.8 \pm 0.1$ & $-2.1 \pm 0.1$ & $-3.4 \pm 0.1$ & $-2.9 \pm 0.1$ \\
\hline$\Delta G^{0}{ }_{m i c}, \mathrm{~kJ} \mathrm{~mol}^{-1}$ & $-20.5 \pm 0.4$ & $-19.1 \pm 0.4$ & $-21.4 \pm 0.5$ & $-22.0 \pm 0.5$ \\
\hline \multicolumn{5}{|c|}{$\begin{array}{l}\text { SDS/TX100 } \\
\end{array}$} \\
\hline$\alpha_{T X 100}$ & 0.2 & 0.4 & 0.6 & 0.8 \\
\hline$x^{m}$ & $0.72 \pm 0.02$ & $0.77 \pm 0.02$ & $0.70 \pm 0.02$ & $0.79 \pm 0.02$ \\
\hline $\boldsymbol{\beta}^{m}$ & $-2.3 \pm 0.1$ & $-2.9 \pm 0.1$ & $-3.6 \pm 0.1$ & $-3.8 \pm 0.1$ \\
\hline$\Delta G^{0}{ }_{m i c}, \mathrm{~kJ} \mathrm{~mol}^{-1}$ & $-21.5 \pm 0.4$ & $-22.2 \pm 0.5$ & $-20.8 \pm 0.4$ & $-22.4 \pm 0.5$ \\
\hline
\end{tabular}

a)

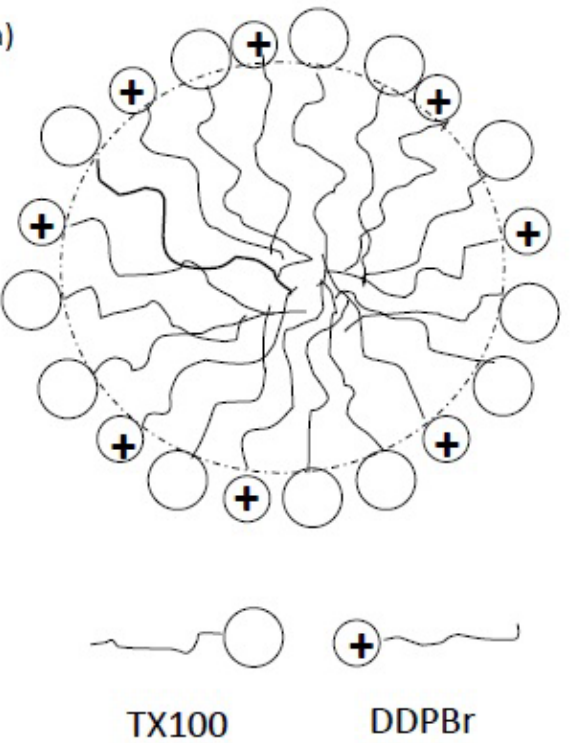

b)
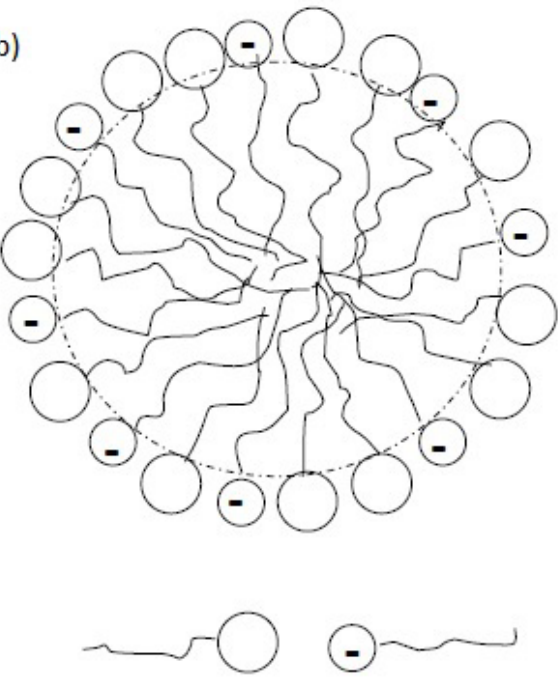

TX100

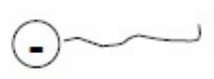

SDS

Fig. 3. Schematic presentation of the mixed DDPBr/TX100 (a) and SDS/TX100 (b) micelles in the aqueous solution.

In a similar way the molecular interaction parameter $\beta^{\sigma}$ in the mixed adsorption layer at the air/solution boundary was calculated [3]: 


$$
\beta^{\sigma}=\frac{\ln \left(\alpha_{1} C / x_{1}^{\sigma} C_{1}^{0}\right)}{\left(1-x_{1}^{\sigma}\right)^{2}}
$$

where, $C^{0}{ }_{1}$ and $C$ are the concentrations of the solution of surfactant 1 and the surfactant mixture at the given surface tension value; $x_{1}^{\sigma}$ and $\alpha_{1}$ are molar fractions of surfactant 1 in the mixed surface layer and in the solution, respectively.

The distribution of the components in the mixed adsorption layer was evaluated from the equation

$$
\left(x_{1}^{\sigma}\right)^{2} \ln \left(\frac{\alpha_{1} C}{C_{1}^{0} x_{1}^{\sigma}}\right)=\left(1-x_{1}^{\sigma}\right)^{2} \ln \left(\frac{\alpha_{2} C}{C_{2}^{0}\left(1-x_{1}^{\sigma}\right)}\right)
$$

where, $C^{0}{ }_{1}, C_{2}^{0}$ and $C$ correspond to concentrations of surfactants 1,2 and the surfactant mixture at the given surface tension value; $x_{1}^{\sigma}$ and $\alpha_{1}$ are the surfactant 1 fractions in the surface layer and in the solution, respectively

In general, the surfactants' composition in the mixed adsorption layer (at the given surface tension) might be evaluated taking into account the bulk concentrations of the single and mixed surfactant solutions. The negative values of $\beta^{\sigma}$ parameter presented in Table 3 indicate strong attraction of the surfactant molecules and ions in the mixed adsorption layers. Such interactions are more pronounced in SDS/TX100 mixtures as the absolute values of $\beta^{\sigma}$ are larger for these mixtures compare to $\beta^{\sigma}$ values for DDPBr/TX100 systems.

Table 3. Molar fraction of TX100 in an adsorption layer $x^{\sigma}$, molecular parameter $\beta^{\sigma}$ and $\Delta G^{0}$ ads values in the

\begin{tabular}{|c|c|c|c|c|}
\hline \multicolumn{5}{|c|}{ DDPBr/TX100 } \\
\hline$\alpha_{T X 100}$ & 0.2 & 0.4 & 0.6 & 0.8 \\
\hline$x^{\sigma}$ & $0.80 \pm 0.02$ & $0.83 \pm 0.02$ & $0.87 \pm 0.02$ & $0.89 \pm 0.02$ \\
\hline$\beta^{\sigma}$ & $-1.2 \pm 0.1$ & $-2.5 \pm 0.1$ & $-3.9 \pm 0.1$ & $-3.2 \pm 0.1$ \\
\hline$\Delta G^{0}{ }_{a d s}, \mathrm{~kJ} \mathrm{~mol}^{-1}$ & $-22.1 \pm 0.5$ & $-23.3 \pm 0.5$ & $-24.0 \pm 0.6$ & $-25.1 \pm 0.6$ \\
\hline \multicolumn{5}{|c|}{ SDS/TX100 } \\
\hline$\alpha_{T X 100}$ & 0.2 & 0.4 & 0.6 & 0.8 \\
\hline$x^{\sigma}$ & $0.71 \pm 0.01$ & $0.76 \pm 0.01$ & $0.78 \pm 0.01$ & $0.80 \pm 0.02$ \\
\hline$\beta^{\sigma}$ & $-2.1 \pm 0.1$ & $-4.2 \pm 0.1$ & $-6.5 \pm 0.1$ & $-6.0 \pm 0.1$ \\
\hline$\Delta G_{a d s}^{0}, \mathrm{~kJ} \mathrm{~mol}^{-1}$ & $-23.2 \pm 0.5$ & $-24.5 \pm 0.6$ & $-26.2 \pm 0.6$ & $-25.4 \pm 0.6$ \\
\hline
\end{tabular}
surfactant systems at surface tension of $35 \mathrm{~mJ} \mathrm{~m}^{-2}$

Table 3 shows that $x^{\sigma}$ values for both SDS/TX100 and DDPBr/TX100 mixtures are notably higher than the relevant $\alpha_{T X 100}$ values. These findings prove the mixed adsorption layer is enriched with the nonionic surfactant at the air/solution boundary. The analysis of the molecular interactions among the nonionic and cationic/anionic surfactants in the mixed adsorption layer indicate that $\beta^{\sigma}$ and the standard free adsorption energies $\Delta G^{0}$ ads values are higher in the surfactant mixtures at a high TX100 content $\left(\alpha_{T X 100}=0.6-0.8\right)$.

Thus, as seen from the obtained experimental data for mixed DDPBr/TX100 and SDS/TX100 systems, a synergetic effect related to decreasing the surface tension was found. This was true when at the same total surfactant concentrations, the surface tension of the surfactant mixture was smaller comparing to the surface tension in the single surfactant solutions. On the other hand, the obtained data showed a lack of synergism related to the micelle formation in the surfactant's mixtures. Obviously, a notable difference in the surfactants' $C M C$ values is a rationale for a lack of synergism during micelle formation process. The nonionic micelles in the surfactant mixture are formed much earlier than micelles of the ionic surfactants. The maximum $\beta^{m}$ readings (by the absolute value) in the mixed micelles correspond to the surfactant mixtures at $\alpha_{T X 100}=0.6-0.8$. 
Negative deviation from the ideal behaviour, which is related to decreasing the surface tension in DDPBr/TX100 and SDS/TX100 surfactant mixtures, might be explained by the influence of molecular interactions among TX100 and the ionic surfactants in the mixed adsorption layer [24,25]. As was reported different types of molecular interactions including electrostatic, ion-dipole and van der Waals interactions occur in the mixed surfactants systems [8]. Before mixing the surfactants, there are repulsive electrostatic forces among the molecules of ionic surfactant (DDPBr or SDS) that bear the similar charge in the solution. These electrostatic interactions become weaker after mixing with the nonionic TX100 surfactant due to dilution. The decreasing of repulsive electrostatic forces amid the ionic surfactant molecules is obviously a main reason of increasing the negative $\beta^{\sigma}$ parameters in the surfactant mixtures, which consist of the nonionic and ionic counterparts. On the other hand, the attractive van der Waals forces between hydrophobic residues of the molecules of the surfactants enhance the molecular contacts in the ionic/nonionic mixtures and by this also contribute to larger negative values of $\beta^{\sigma}$ in the surfactant systems.

The obtained data show that the mixed adsorption layer had different composition compared to the composition in the bulk of the binary surfactant's solution. The mixed micelles and adsorption layers in the surfactant mixtures were enriched with TX100 counterpart with greater surface activity. For both $\mathrm{DDPBr} / \mathrm{TX} 100$ and SDS/TX100 systems, the synergetic effects are most prominent at high content of the nonionic surfactant $\left(\alpha_{T X 100}=0.6-0.8\right)$. However, $\beta^{m}$ and $\beta^{\sigma}$ parameters are notably higher for SDS/TX100 system compared to DDPBr/TX100 mixture. The strengthening of the intermolecular interactions in the SDS/TX100 mixture might be due to the coordination of the oxyethylene chain of TX100 macromolecule with the SDS anion. It was previously reported that oxyethylene groups of a nonionic surfactant can complex with counter ions of an anionic surfactant [26].

\section{Conclusion}

The effect of molecular interactions on the surface activity of binary mixtures of nonionic TX100 with ionic DDPBr and SDS surfactants was investigated. The ionic surfactants have hydrophobic alkyl chains of the same size but different polar groups. A feature of the systems studied is notable dissimilarity in the $C M C$ values and in surface activity of the individual surfactants.

By using the Ruben-Rosen and Rosen-Aronson models, molecular interaction parameters in the mixed micelles $\beta^{m}$, and in the adsorption layers $\beta^{\sigma}$, composition of mixed micelles/adsorption layers, as well as $\Delta G^{0}{ }_{\text {mic }}$ and $\Delta G^{0} a d s$ values were evaluated. Synergism related to reducing the surface tension in the surfactant mixtures was found while no deviations from the ideal behaviour in the micelle formation was observed.

It was shown that the mixed adsorption layers and the micellar phases are enriched with TX100 surfactant and such enrichment is the largest at $\alpha_{T X 100}=0.6-0.8$. Both for SDS/TX100 and DDPBr/TX100 systems, the synergetic effects as well as negative values of $\beta^{\sigma}$ and $\Delta G^{0}$ ads parameters are most pronounced at a high TX100 molar fraction in the surfactant mixtures. The negative readings of $\beta^{\sigma}$ parameter indicate that attraction of the molecules and ions in the mixed adsorption layers occur.

It should be highlighted that $\Delta G^{0} a d s, \beta^{m}$ and $\beta^{\sigma}$ values are notably higher for SDS/TX100 mixture compared to DDPBr/TX100 system. This difference might be explained by strengthening of the intermolecular interactions due to chelating of the oxyethylene groups of TX-100 with the SDS anions.

\section{Acknowlegement}

The authors would like to thank Ministry of Education and Science of Ukraine for support this work through the Grant No. 110/103-F. 


\section{References}

1. Rosen, M.J. Surfactants and Interfacial Phenomena. Wiley-Interscience, New York, 2004.

2. Penfold, J.; Staples, E.J.; Tucker, I.; Thomas, R.K. Colloids Surf. A: Physicochem. Eng. Asp. 1999, 155, 11-26; DOI: 10.1021/la0002637

3. Rosen, M.J.; Zhou, Q. Langmuir. 2001, 17, 3532-3537. DOI: 10.1021/la001197b

4. Holland, P.; Rubingh, D., in Cationic Surfactants, Vol. 37, Holland, P.; Rubingh, D. (Eds.), Marcel Dekker, New York, 1991, 141-187.

5. Scamehorn, J.F., in: Phenomena in Mixed Surfactant Systems, ACS Symposium Series 311, Scamehorn J.F. (Ed.), ACS, Washington, DC, 1986, 1-27

6. Janczuk, B.; Zdziennicka, A.; Wojcik, W. Colloids Surf. A: Physicochem. Eng. Asp. 2003, 220, 61-68. DOI: 10.1016/S0927-7757(03)00060-8

7. Hua X.Y., Rosen M.J. Synergism in binary mixtures of surfactants. 1. Theoretical analysis. J. Colloid Interf. Sci. 1982, 90, 212-219. DOI: https://doi.org/10.1016/0021-9797(82)90414-3

8. Zhou, Q.; Rosen, M. J. Langmuir 2003, 19, 4555-4562; DOI: 10.1021/la020789m

9. Szymczyk, K.; Janczuk, B. Colloids Surf. A: Physicochem. Eng. 2007, 293, 39-50. DOI: 10.1016/j.colsurfa.2006.07.006

10. Zdziennicka, A.; Szymczyk, K.; Krawczyk, J.; Janczuk, B. Fluid Phase Equil. 2012, 318, 25-33. DOI:10.1016/j.fluid.2012.01.014

11. Wang, Y.; Marques, E.F.; Pereira, C.M. Thin Solid Films 2008, 516, 7458-7466. DOI: 10.1016/j.tsf.2008.03.029

12. Geng, T.; Zhang, C.; Jiang, Y.; Ju, H.; Wang, Y. J. Mol. Liquids 2017, 232, 36-44. DOI: http://dx.doi.org/10.1016/j.molliq.2017.02.055

13. Bakshi, M.S.; Singh, J.; Singh, K.; Kaur, G. Colloids Surf. A: Physicochem. Eng. Asp. 2004, 237, 6171. DOI: 10.1016/j.colsurfa.2004.01.030

14. Kochkodan, O.; Antraptseva, N.; Kochkodan, V. Material Science Forum. 2018, 936, 8-13. DOI: https://doi.org/10.4028/www.scientific.net/MSF.936.8

15. Javadian, S.; Kakeman, J. J. Mol. Liquids 2017, 242, $115-128 . \quad$ DOI: https://dx.doi.org/10.1016/j.molliq.2017.06.117

16. Cirin, D.; Krstonosic, V.; Sazdani, D. Fluid Phase Equil. 2018, 473, 220-225, DOI: https://doi.org/10.1016/j.fluid.2018.06.009

17. Bagheri, A.; Paresa, K. $R C S A d v$. 2017, 7, 18151-18161. DOI: 10.1039/C6RA27382C

18. Le, T.N.; Phan, C.M.; Nguyen, A.V.; Ang. H.M. Minerals Eng. 2012, 39, 255-261. DOI: http://dx.doi.org/10.1016/j.mineng.2012.06.003

19. Adamson, A.W.; Gast, A.P. Physical Chemistry of Surfaces (sixth ed). John Wiley \& Sons, Inc., New York, 1997.

20. Clint J.H. Micellisation of mixed nonionic surface active agents. J. Chem. Soc. Faraday Trans. 1975, 71, 1327-1334. DOI: 10.1039/F19757101327

21. Rosen, M. J.; Sultana, S.B. J. Colloid Interf. Sci. 2001, 238, 528-534. DOI: DOI: $10.1006 /$ jcis.2001.7537

22. Rusanov, A.I. Micelle formation in surfactants solutions. Khimiya, St. Petersburg, 1992

23. Moore, S.A.; Glenn, K.M.; MacDonald, A.M.; Palepu, R M. Colloid Polym. Sci. 2007, 285, 543-552. DOI: $10.1007 / \mathrm{s} 00396-006-1604-6$

24. Maeda, H.J. J. Colloid Interf. Sci. 1995, 172, 98-105. DOI: https://doi.org/10.1006/jcis.1995.1230.

25. Goloub, T.P.; Pugh, R.J.; Zhmud, B.V. J. Colloid Interf. Sci. 2000, 229, 72-81. DOI: 10.1006/jcis.2000.6954

26. Rozen, M.J.; Zhao, F. . J. Colloid Interf. Sci. 1983, 95, 443-452. DOI: https://doi.org/10.1016/00219797(83)90204-7 